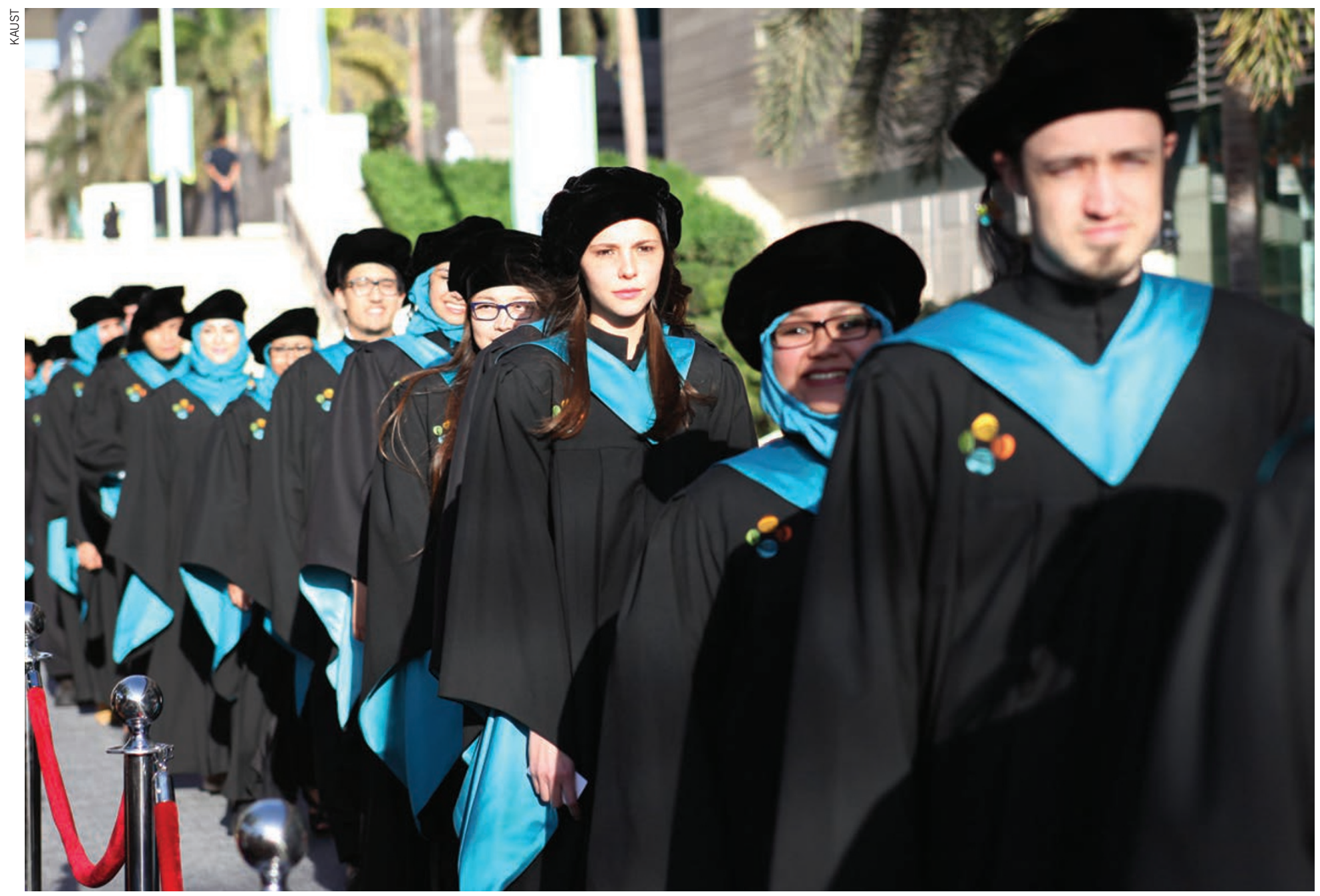

KAUST students embark on a new school year with a commencement ceremony. The relatively new university has quickly made an impact on the Nature Index.

\title{
OILING THE WHEELS ON A ROAD TO SUCCESS
}

With the benefit of a sustainable plan and the funds to back it, Saudi Arabia is aiming high.

\section{BY PAKINAM AMER}

audi Arabia's scientific development

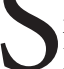
may be in its infancy, but the oil-rich

Kingdom is making strides in terms of research investment and publication - with a clear ambition to one day join those in the highest echelons.

In 2012, Saudi Arabia had a weighted fractional count (WFC) of 52.84 in the index, sitting behind Turkey, Iran, Mexico, Chile and South Africa. In four years it rose $86.8 \%$ to reach a WFC of 98.67 , leapfrogging all these countries to compete with Chile and Argentina globally. Saudi Arabia ranks at number 31 in the world in terms of WFC up from 39 in 2012.

The country has risen even higher in specific subject areas. In chemistry, for example, it has surpassed countries with a strong scientific impact like Finland and Ireland,

with its WFC rising to 66.54 , achieving almost a three-fold increase from its position in 2012.

Institutionally, the country's leading science hub King Abdullah University of Science and Technology (KAUST) made an impressive leap in its WFC between 2012 and 2015, carving a place for itself to compete with American and European research powerhouses.

In just four years, its WFC has risen to become higher than those of prestigious institutions including the European Organization for Nuclear Research (CERN),

"Its rise up the ranks depends on a 'selfcorrecting mechanism' of a slow start to sustainable growth.' output of all of these institutions dwarfed KAUST's in 2012, but KAUST's impressive trajectory since then has seen its WFC shoot to 72 in 2015 , overtaking these heavy-hitters.

The country's science development ambitions have been backed by action. Since 2008, the country has embarked on a multi-tiered strategy that will see the Kingdom overhaul its science infrastructure, build high-spec labs secure grants for research in priority areas in applied science, and link science to industries that drive the economy.

The strategy, broken into four stages to be implemented by 2030, aims to eventually "see Saudi Arabia become a leader in Asia and give it an economic power based on science," says Abdulaziz Al-Swailem, vice president of scientific research support at King Abdulaziz City for Science and Technology (KACST).

The Kingdom's science investments focus on applied research that feeds directly into the 


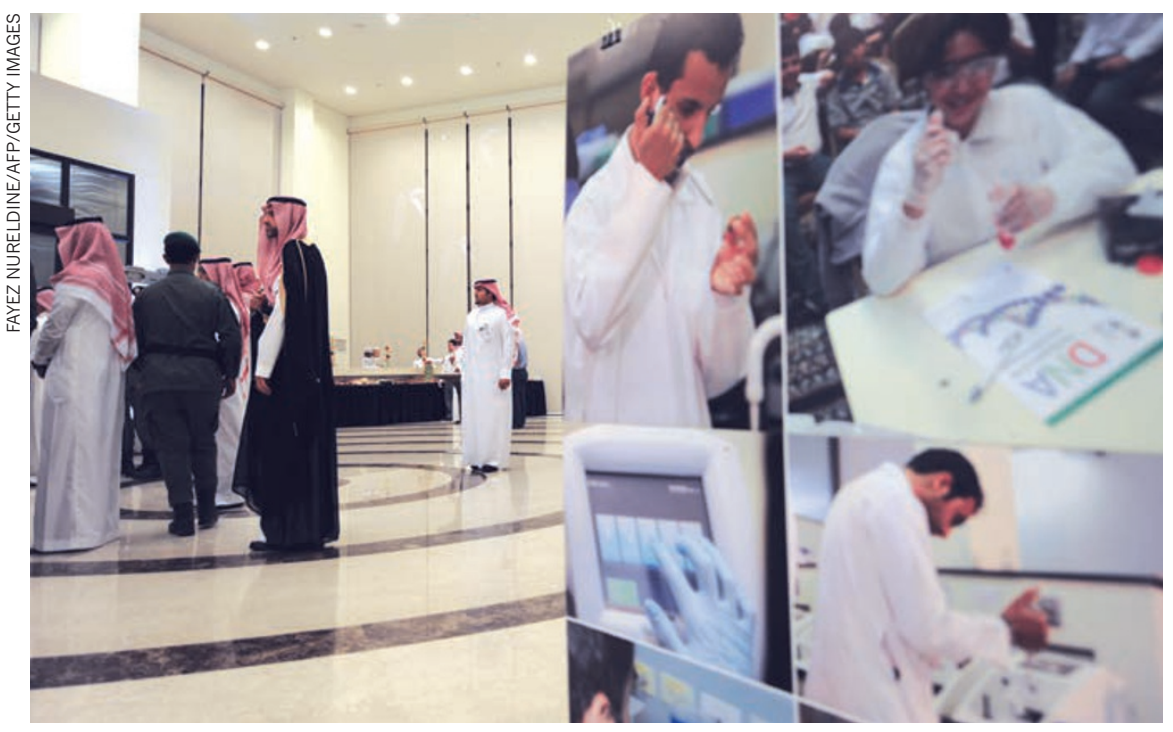

The Saudi Human Genome Project will sequence 100,000 human genomes to conduct biomedical research in the Saudi population.

\section{SAUDI ARABIA'S MARCH TO THE TOP}

Saudi Arabia's efforts to boost its scientific research have been paying off, with its output in the Nature Index (WFC) rising steadily over the years. The two graphs below highlight Saudi Arabia's rise compared to other nations, both overall and for chemistry.

\section{OVERALL OUTPUT}

In 2012 Saudi Arabia's overall output in the index was below all the countries shown, but continuous efforts have seen the Kingdom's WFC rise to overtake them all in 2015.

Saudi Arabia
Chile
Argentina
Mexico
Hungary
South Africa
Greece
Iran
Turkey

\section{CHEMISTRY}

More marked than its overall rise, Saudi Arabia has made great strides in chemistry. After accelerated growth, which saw the Kingdom's chemistry WFC triple since 2012, it has outshone many larger players in the field in 2015.

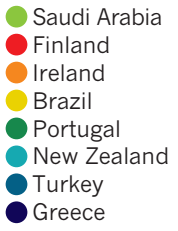

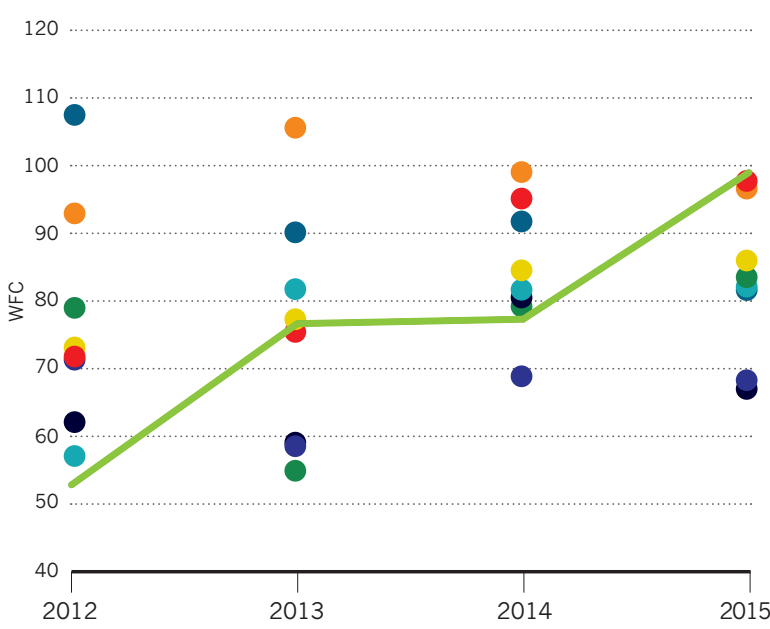

80

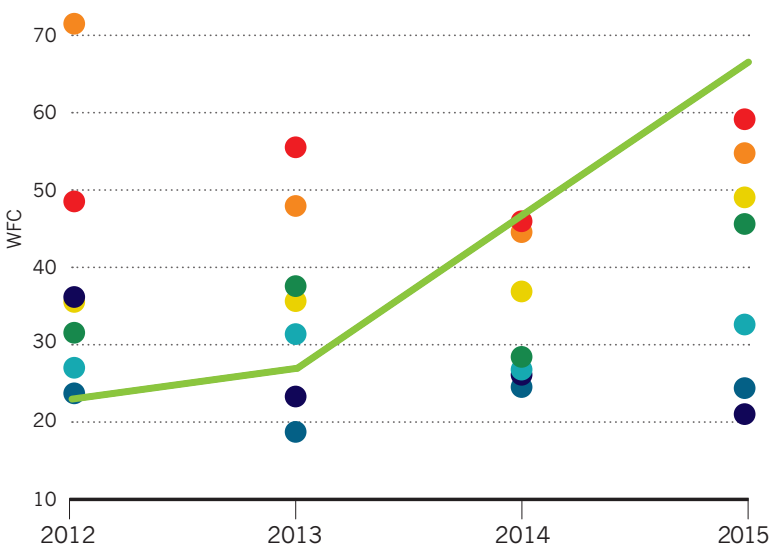

country's industrial interests, particularly the oil and energy sector. But even in its strong subjects, chemistry and the physical sciences, Saudi Arabia's WFC remains modest compared to big players in Asia like China, Japan and South Korea.

To truly swim comfortably with these bigger fish, Saudi Arabia may benefit from looking at successful emerging economies in Asia.

One inspiration could be India. In addition to multi-disciplinary scientific and technical advancements that have improved its output in the index from 736.5 to 901.4 in the past four years, the subcontinental giant has joined the exclusive club of countries that have launched successful space missions.

Like Saudi Arabia, India's leading research institutes focus on chemistry, and their total output currently outstrips their Saudi Arabian counterparts by almost a factor of seven (the latter surpassing 472 in 2015, while the former is 66.5).

India's prowess in chemistry is something that Saudi Arabia can aspire to, considering that working conditions for researchers in the Kingdom are more conducive.

India's science ecosystem is far from perfect. Research funding cannot keep up with inflation and a general slowdown in the country's economy. In addition, commentators from the research community say the funding processes are lengthy, bureaucratic, and provide little feedback when applications for grants are turned down. Meanwhile, Saudi Arabia's healthy stream of oil revenue provides assured funding for the country's state-of-the-art research facilities.

While India has slightly increased spending and dedicated US $\$ 1.19$ billion for the next fiscal year (2016-2017) for science, it has around 700 universities and 200,000 full-time researchers drawing on the same funding pot. By contrast, Saudi Arabia has pledged an education and training budget of US $\$ 50.9$ billion for next year, which includes higher education and scientific research. With a total population of just 30 million, it has a much lower number of full-time researchers competing for the available resources.

Another impressive trajectory that Saudi Arabia might look to emulate is that of Singapore, which has a smaller population as well and has managed to climb high in the index. Like the Kingdom, Singapore also has a focus on chemistry research, and it has put together a similar top-down national science strategy for research institutes across the country. Both countries have strong collaborations with top universities around the world and are welcoming of foreign researchers in their efforts to drive innovation.

Mansour Alghamdi, director of the general directorate of scientific awareness and publishing at KACST, is optimistic that Saudi Arabia can bridge the large gap that currently exists in the volume of scientific 
output between it and such countries as India and Singapore.

"The Kingdom of Saudi Arabia has a clear plan to do so and it has the resources," he says.

\section{FUTURE GROWTH}

In 2012, Saudi's ranking in research output, with a WFC of 52.8, meant it was comparable with countries like South Africa, Turkey and Iran, all hovering around the 60-70 mark. Its WFC stood way below countries like Mexico, Hungary, Chile, Greece and Argentina.

Four years later, the country's research outlook is very different and it is surpassing countries like Argentina, Mexico and Hungary in the index, and levelling the playing field with Chile. Chemistry research led the country's rapid rise to surpass these countries, but its life sciences and physical sciences WFCs of 8.5 and 31.5 still lag behind.

However, the Kingdom's AC has been steadily growing in these two fields over the past four years, hinting at the ever-increasing significance of international collaborations. It seems that Saudi Arabian researchers are casting their nets ever wider and are participating in publishing more articles, to the detriment of the WFC accredited for these articles.

Though international collaboration has proved fruitful, Saudi Arabia must keep a focus on nurturing home-grown talent, says Nasser Al-Aqeeli, dean of research at King Fahd University of Petroleum \& Minerals (KFUPM), based in Dhahran's 'techno

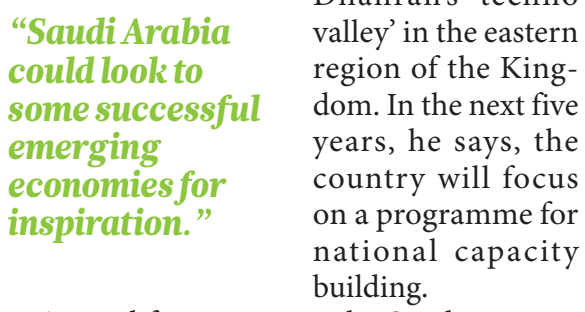

A good first step was the Saudi government's decision to create a large scholarship programme in 2005, arguably the largest in the world, which has seen more than 200,000 young Saudi Arabians studying abroad. This makes Saudi Arabian students in the United States the fourth largest bloc of expatriate students, following those of China, India and South Korea. The government hopes these students will come back and drive a scientific culture in the country.

Saudi Arabia is also looking to increase its applied research focus, which is an integral part of the current phase of its national science strategy, while securing good funding for basic research as well. Al-Aqeeli says that Saudi's journey involves what he termed a "self-correcting mechanism" where the country is having a slow start in high-impact research, but a more sustainable one. An eventual future move towards basic research might help Saudi Arabia's research capacity to mature.

\section{AN INTERNATIONALLY RISING STAR}

This graph shows KAUST's rise compared to a selection of other institutions*.

King Abdullah University of Science \& Technology (KAUST)

Brookhaven National Laboratory (BNL)

The University of Georgia (UGA)

University of Glasgow

Shandong University (SDU)

Johannes Gutenberg

University Mainz (JGU)

University of Waterloo

University of Tübingen

Dresden University of

Technology (TU Dresden)

Radboud University Nijmegen (RU)

European Organization

for Nuclear Research (CERN)

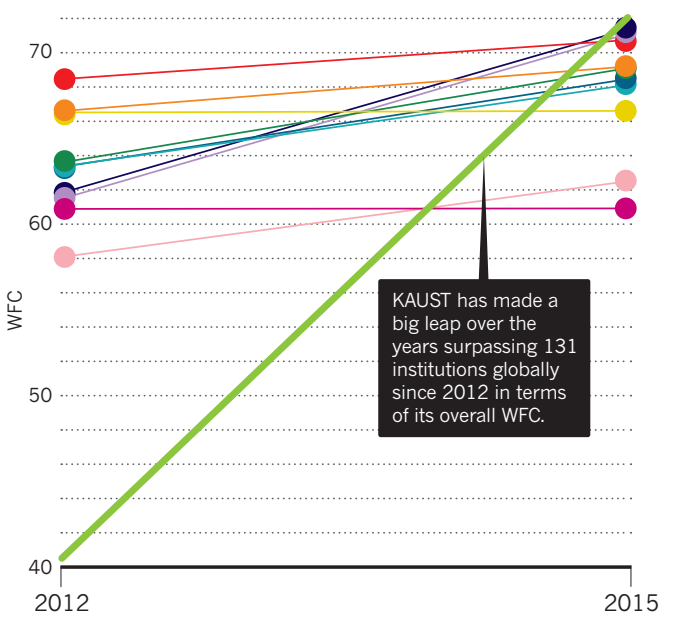

*Institutions shown are those that were furthest above KAUST in 2012, have experienced overall growth in WFC by 2015 and have been overtaken by KAUST in 2015. For clarity, only 2012 and 2015 data points are shown.
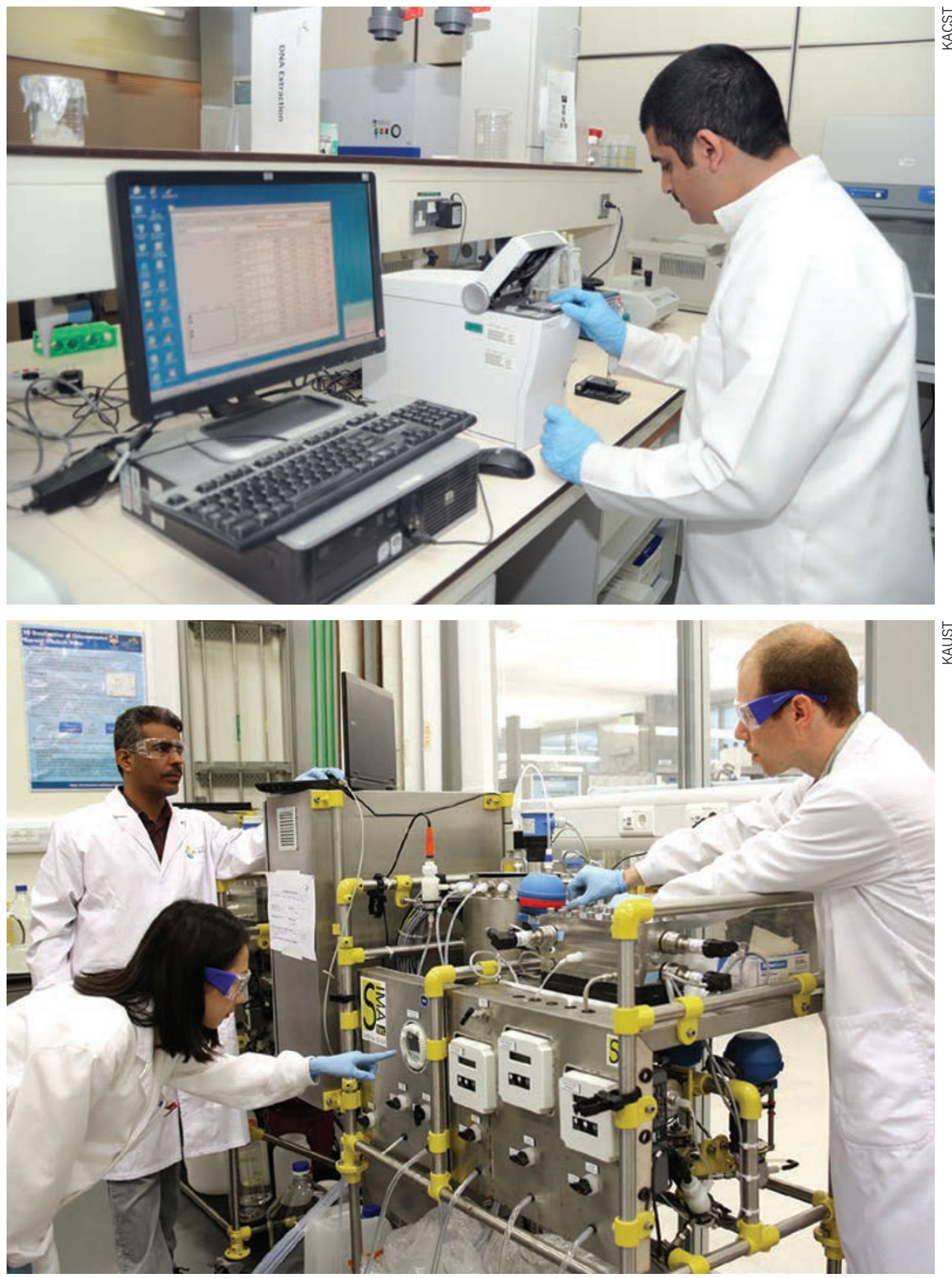

Saudi Arabian researchers benefit from cutting-edge labs and generous funding that has boosted the country's R\&D. 